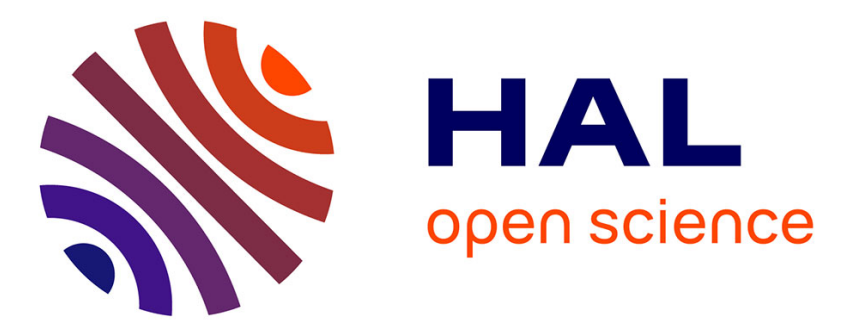

\title{
Primary cesarean delivery rate: Potential impact of a checklist
}

M. Toumi, E. Lesieur, J.-B. Haumonte, C. D'ercole, F. Bretelle

\section{To cite this version:}

M. Toumi, E. Lesieur, J.-B. Haumonte, C. D'ercole, F. Bretelle. Primary cesarean delivery rate: Potential impact of a checklist. Journal of Gynecology Obstetrics and Human Reproduction, 2018, 47 (9), pp.419-424. 10.1016/j.jogoh.2018.08.006 . hal-02006618

\section{HAL Id: hal-02006618 https://hal-amu.archives-ouvertes.fr/hal-02006618}

Submitted on 12 Apr 2019

HAL is a multi-disciplinary open access archive for the deposit and dissemination of scientific research documents, whether they are published or not. The documents may come from teaching and research institutions in France or abroad, or from public or private research centers.
L'archive ouverte pluridisciplinaire HAL, est destinée au dépôt et à la diffusion de documents scientifiques de niveau recherche, publiés ou non, émanant des établissements d'enseignement et de recherche français ou étrangers, des laboratoires publics ou privés. 


\title{
Primary cesarean delivery rate: Potential impact of a checklist
}

\author{
M. Toumi ${ }^{\mathrm{a}, \mathrm{b}}$, E. Lesieur ${ }^{\mathrm{a}, \mathrm{b}}$, J.-B. Haumonte ${ }^{\mathrm{a}, \mathrm{c}}$, J. Blanc ${ }^{\mathrm{a}, \mathrm{b}}$, C. D'ercole ${ }^{\mathrm{a}, \mathrm{b}}$, F. Bretelle ${ }^{\mathrm{a}, \mathrm{b}, \mathrm{d}, \mathrm{e}, *}$ \\ ${ }^{a}$ University Hospital centers Nord and Conception in Marseille, France \\ ${ }^{\mathrm{b}}$ Department of Gynaecology and Obstetrics, Gynepole, AP-HM, Assistance Publique-Hôpitaux de Marseille, AMU, Aix-Marseille Université, France \\ ${ }^{\mathrm{c}}$ Hôpital St Joseph, Marseille, France \\ ¿ Réseau Méditerranée (PACA Corse Monaco), France \\ e Unité de Recherche sur les Maladies Infectieuses Tropicales et Emergentes, UM63, CNRS 7278, IRD 198, INSERM 1095, Marseille, France
}

\section{A R T I C L E I N F O}

\section{Article history:}

Received 26 April 2018

Received in revised form 9 July 2018

Accepted 20 August 2018

Available online 24 August 2018

\section{Keywords:}

Cesarean section

First cesarean delivery

Arrest of labor

Breech presentation

Suspected fetal macrosomia

\begin{abstract}
A B S T R A C T
Background. - Cesarean section is the most common surgical procedure performed in developed countries. Its incidence is increasing to a worrisome extent. The 2003 French National Perinatal Survey showed that the inflation in the overall cesarean rate was mainly due to an increase in the first cesarean delivery rate.

Objective. - To evaluate a new tool: a checklist that intent to decrease the first cesarean delivery rate. Study design. - Retrospective, observational, multi-center study. A new tool, a "First cesarean delivery" checklist was built according American and French guidelines. Women with full-term of pregnancy, nulliparous or multiparous with a first caesarean delivery including arrest of labor, breech presentation or suspected fetal macrosomia were included. The checklist was applied. Potentially preventable cesareans were analyzed.

Results. - Among 571 first cesarean section, 178 were eligible to check list application. 147 charts were analyzed in the study. $11.9 \%$ of first cesarean deliveries performed were potentially avoidable after applying the checklist. This represented $6.6 \%$ of all cesareans.

Conclusion. - The checklist based on the recall of good practices could be an interesting tool to decrease the first cesarean rate.
\end{abstract}

(c) 2018 Elsevier Masson SAS. All rights reserved.

\section{Introduction}

Cesarean section is the most common surgical procedure performed in developed countries. Its incidence is increasing worryingly [1]. An American study published showed that $50 \%$ of the increase in the number of cesarean sections was due to the first cesarean rate [2]. For Zhang et al., iterative cesareans after a uterine scar contributed to $45.1 \%$ of scheduled cesareans and to $30.9 \%$ of all cesareans performed in the United States between 2002 and 2008 [3]. In France, cesarean delivery rose from $10.9 \%$ in 1981 to $20.2 \%$ in 2016 [4]. The 2016 French National Perinatal Survey showed that an increase in overall cesarean deliveries was mainly due to first cesarean rate (71.5\%) [5]. Although in certain obstetric situations,

\footnotetext{
* Corresponding author at: Department of Gynaecology and Obstetrics and UMR CNRS-IRD 6236 - Faculté de Médecine de Marseille, Université de la Méditerranée; Hôpital Nord, Department of Gynaecology and Obstetrics, Chemin des Bourrely, 13915 Marseille Cedex 20, France.

E-mail addresses: toumi.myriam@gmail.com (M. Toumi), emmanuelle.lesieur@gmail.com (E. Lesieur),jb.haumonte@gmail.com (J.-B. Haumonte), julieblanc@live.fr (J. Blanc), Claude.D’ERCOLE@ap-hm.fr (C. D’ercole), florence.bretelle@ap-hm.fr (F. Bretelle).
}

cesarean delivery is undoubtedly the only acceptable obstetric outcome in terms of materno-fetal safety, other indications seem to raise questions in terms of the benefit-risk balance. Indeed, a cesarean section remains a surgical intervention that includes short, medium and long-term risks [6].

Efforts are made worldwide to curb the cesarean section rates. In France, in 2012, Guidelines on scheduled cesarean section indications and in 2017 about normal delivery were published [7,8]. In March 2014, the American Congress of Obstetricians and Gynecologists (ACOG) issued recommendations to reduce the number of first cesareans, based on the challenging practices and on remembering good practices [9]. In Canada, in 2015, a team evaluates an interventional strategy to reduce cesarean sections rate. This combined the recall of good practices, the implementation of audits and biofeedback for the obstetrical team. A significant reduction in the overall rate of cesarean was thus demonstrated, in hospitals where the "interventional" training strategy was implemented [10]. A French uni-centric study carried out at the University Hospital of Grenoble in 2015 based on the same type of approach gave similar results [11]. 
Our objective was to evaluate the potential impact of a checklist with the aim to decrease first cesarean delivery.

\section{Materials and methods}

This is a retrospective multi-center study. Our objective was to analyze the impact of the "First cesarean delivery" checklist on the first cesarean rate. The project was approved by the Research Ethics Committee on Obstetrics and Gynecology (CEROG) in 2016, under the notice number CEROG OBS 2016-08-30.

\section{Patients}

Women who underwent a first cesarean delivery between November 1st 2014 and September 1st 2015 in the University Hospital centers Nord and Conception in Marseille, France were selected. Women with full-term of pregnancy (gestational age $\geq 37$ weeks of gestation), nulliparous or multiparous with an exclusive history of vaginal delivery and with an indication for a cesarean section according to the checklist were eligible. Women matching the checklist eligibility criteria and whose medical records were searchable were included in the study for analysis, they gave their reasoned and informed consent to be part of the study. The noninclusion criteria were: prematurity (gestational age $<37$ weeks of gestation), multiple gestation, united and multi-scarred uterus, history of uterine surgery with uterine cavity intrusion (e.g. polymyomectomy), immediate emergencies or suspected materno-fetal risks (retro placental hematoma, pre-eclampsia, cord prolapse, metrorrhagia, placenta previa) and non-reassuring fetal heart-rate (FHR) tracing according to CNGOF 2007 guidelines.

\section{Study design}

The checklist was based on the French recommendations and American expert opinion and (Fig. 1). Data were collected retrospectively from the maternity birth registers by one investigator. The checklist was next applied to cesareans that meet the eligibility and inclusion criteria. We then evaluated the first cesareans that were potentially preventable after applying the checklist. Suspected macrosomia was defined by a fetal estimated ultrasound weight greater than $90^{\circ}$ percentile according to Hadlock.

\section{Outcomes}

The primary outcome was the rate of potentially preventable first cesareans after applying the checklist. The rate of potentially preventable cesarean section was assimilate to the rate of non conformity to check list with at least one missing criteria. A cesarean was considered as potential preventable or avoidable if at least one more criteria of the check list was not present (Fig. 1).

The secondary outcomes were: indications for first cesarean delivery, overall cesarean rate in general, overall cesarean rate potentially preventable after applying the checklist, analysis of the different missing check-list criteria according to the first cesarean indications.

\section{Statistical analysis}

Quantitative data were expressed as an average with standard deviation. Qualitative data were reported as numbers and percentages. Statistical analysis was performed with the IBM SPSS Statistics version 20 software.

\section{Results}

Among the study period 571 patients that underwent cesarean section, 178 women with a first cesarean delivery were eligible for the application of the checklist. Thirty-one medical charts could not be analyzed.

One hundred and forty-seven women were therefore included in the retrospective analysis (Fig. 2). Among them, 68 (46.2\%) were potentially preventable after applying the checklist. Among them 47 Cesarean with arrest of labor, 14 women with breech presentation and for 7 patients with suspected fetal macrosomia. Characteristics of the study population are shown in Table 1. Indications for first cesarean delivery are given in Table 2. The overall rate of caesarean section was $23.2 \%$ (1035/4467 deliveries). The first cesarean rate was $12.8 \%$ (571/4467). $55.2 \%$ of the cesareans performed were first cesareans (571/1035).

Concerning our primary outcome, $11.9 \%$ of first cesarean deliveries performed were potentially preventable after applying the checklist (68/571). This represented $6.6 \%$ of all cesarean sections (68/1035).

The description of non-conformity to check-list criteria according to the cesarean indications can be found below $(n=68)$ :

\section{Arrest of labor (number $=47$ patients)}

- During first stage of labor and latency phase (cervical dilatation $<6 \mathrm{~cm}$ ). Sixteen patients had at least a non-conformity to checklist criterion. When the decision to perform a cesarean was made, the mean cervical dilatation was $4.2 \mathrm{~cm}( \pm 1.04)$ and the mean duration of arrest of labor was $3.76 \mathrm{~h}( \pm 1.69)$.

- During first stage of labor and active phase (cervical dilatation $\geq$ $6 \mathrm{~cm}$ ). Eleven patients had at least one non-conformity to checklist criterion with an arrest of labor of less than $4 \mathrm{~h}$. The mean time of labor arrest when the decision to perform a cesarean has been made was $2.75 \mathrm{~h}( \pm 0.88)$.

- In the second stage of labor: full cervical dilatation, with nonengagement of the fetal head, 20 patients had an arrest of labor of less than $3 \mathrm{~h}$. The average delay of dilatation when cesarean section was performed was $2.6 \mathrm{~h}( \pm 0.67) .6$ additional patients had at least one non-conformity criteria to check-list with no manual rotation of the fetal occiput of a transverse or posterior position or a misdiagnosis of o posterior position.

\section{Breech presentation $(\mathrm{n}=14$ patients)}

- For fourteen patients had at least one non-conformity criteria to check-list and then cesarean section could possibly preventable. External manoeuver version was not proposed to 7 patients and refused by 7 .

\section{Suspected fetal macrosomia ( $\mathrm{n}=7$ patients)}

- Seven patients had at least one check-list criteria missing and then avoidable. In the absence of associated diabetes, 4 patients had a first cesarean even though the fetal weight estimate was less than $5000 \mathrm{~g}$. In the case of diabetes, 3 had a first cesarean even though the fetal weight estimate was less than $4250 \mathrm{~g}$.

\section{Discussion}

Our results show that $11.9 \%$ of first cesarean deliveries were potentially preventable after applying the checklist (i.e. with at least one non conformity criteria). This represented $6.6 \%$ of all cesarean sections. This projection exercise is certainly questionable and rough but it suggests the potential interest of this checklist in clinical practice. Based on literature data, and for each situation the potential rate of vaginal delivery, 38 patients out of 


\section{FIRST CESAREAN DELIVERY CHECKLIST}

Patient data

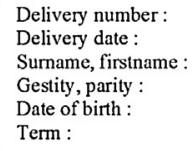

\section{ARREST OF LABOR}

\section{$1^{\text {rst }}$ stage of labor}

Cervical dilation $<6 \mathrm{~cm}$ : latent phase

Standards of active phase progress should not be applied.

A prolonged latent phase and a slow but progressive labor should

not be an indication for cesarean delivery.

Cervical dilation $\geq 6 \mathrm{~cm}$ : active phase

$\square$ Rupture of membranes

$\square$ Urinary catheterization

$\square$ Position of fetal head controlled by ultrasound

$\square$ Manual rotation of the fetal occiput in case of posterior or

transverse position : $\geq 1$ hour of arrest of labor and $\geq 7 \mathrm{~cm}$ of cervical dilation

$\square$ Optimal uterine motor: 3 to 4 contractions $/ 10 \mathrm{~min}$ and no FHR abnormalities

Yes $\rightarrow$ arrest of labor tolerate according the obstetrical context $=$ 4h

Non $\rightarrow$ Oxcytocin

Non optimal uterine motor despite oxcytocin:

arrest of labor tolerate according the obstetrical context $=4$ to $6 \mathrm{~h}$

\section{BREECH PRESENTATION}

Diagnosed during pregnancy

$\square$ External cephalic version suggested at 36-37 weeks

$\square$ Making external cephalic version

$\square$ Information on the modalities of the vaginal delivery by

breech presentation $+\mathrm{CT}$ pelvimetry

Criteria for a vaginal delivery :

( Primiparous or multiparous

[. Complete or extended breech

4 « Normal» CT pelvimetry : promonto-retro-pubic diameter $\geq 10.5 \mathrm{~cm}$ and median transverse diameter $\geq 12 \mathrm{~cm}$ and bi-spinous diameter $\geq 9.5 \mathrm{~cm}$

․ biparietal diameter $\leq 98 \mathrm{~mm}$

ㄱ Fetal weight estimation $<3800 \mathrm{~g}$

․ No contraindications (Absolutes: fetal head deflexion, fetal pathology at risk of acidosis, placenta previa / Relatives : scarred uterus excepted of history of vaginal delivery, early rupture of membranes out of labor, morbid obesity, imbal ance diabetes, uterine malformation)

- All criteria : vaginal delivery accepted

- $\quad \geq 1$ missing criteria : contraindication to vaginal delivery

\section{NON INCLUSION CRITERIA}

* Gestational age $<37$ weeks of gestation

* Uni and multi-scarred uterus, history of uterine surgery with uterine cavity intrusion

* Immediate emergencies or suspected materno-fetal risks (retro placental hematoma, pre-eclampsia, cord prolapse, metrorrhagia, placenta previa)

* Non-reassuring fetal heart-rate (FHR) tracing

* Multiple gestation

$2^{\text {nd }}$ stage of labor : non-engagement of the fetal head, ful cervical dilatation

$\square$ Urinary catheterization

$\square$ Optimal uterine motor : 3 to 4 contractions $/ 10 \mathrm{~min}$

$\square$ Position of fetal head controlled by ultrasound

$\square$ Therapeutic manual rotation of the fetal occiput in case of posterior or transverse position

$\square$ " Engagement ultrasound » (angle $\geq 120^{\circ}$, head-perineum distance $\leq 5 \mathrm{~cm}$ : in favor of fetal head engagement into maternal pelvis)

If absence of FHR abnormalities, arrest of labor tolerate according the obstrical context $=3 \mathrm{~h}$

Diagnosed during labor

The CT pelvimetry is not compulsory.

$\square$ CT pelvimetry done and " abnormal » : promonto-retro-pubic diameter $<10.5 \mathrm{~cm}$ and $/$ or median transverse diameter $<12 \mathrm{~cm}$ and/or bispinous diameter $<9.5 \mathrm{~cm}$

$\square$ CT pelvimetry not done : if all following criteria are not presents, it's an indication of cesarean

(] Multiparous

口 AND normal pelvis clinically

AND all other vaginal delivery criteria are presents (fetal weight estimation $<3800 \mathrm{~g}$ at term, biparietal diameter $\leq$ $98 \mathrm{~mm}$ )

\section{SUSPECTED FETAL MACROSOMIA}

$\square$ Preexisting or gestational diabetes AND fetal weight estimation $>4250$ ou $4500 \mathrm{~g}$ (at 39 weeks of gestation)

$\square$ Absence of diabetes AND fetal weight estimation $>5000 \mathrm{~g}$

Fig. 1. First cesarean delivery checklist. 


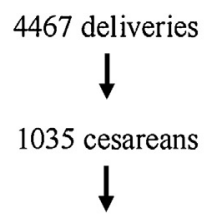

\section{1 first cesareans}

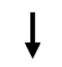

178 eligible patients to the checklist

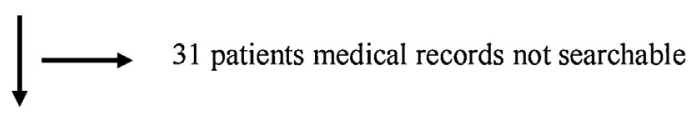

147 patients included for retrospective checklist analysis

89 arrest of labor
25 women :in the
latent phase, first
stage of labor
40 women : in the
active phase, first
stage of labor
24 women : in the
second stage of
labor

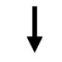

39 breech presentations

- 35 women : diagnosed during pregnancy

- 4 women: diagnosed during labor

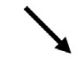

19 suspected fetal mcrosomia

- 15 women : with associated diabetes

- 4 women : without associated diabetes

Fig. 2. Flow chart of cesarean section among the study period including first cesarean section eligible to check list application.

the 68 with at least one non conformity checklist criteria could potentially have a vaginal delivery, i.e. more than half of the patients (55.9\%).

The main indication for a first cesarean delivery was nonreassuring fetal-heart tracing, but this indication was not included

Table 1

Characteristics of the 147 patients included for the retrospective analysis. Values are expressed as mean, standard deviations and in number and percentage.

\begin{tabular}{ll}
\hline Demographic data & Numbers, percentages \\
\hline Age & $29.8( \pm 6.9)$ \\
Gestity & $2.3( \pm 1.8)$ \\
Parity & $0.6( \pm 1.2)$ \\
Hypertension & \\
Pre-existing $<20$ weeks of gestation & $1(0.07 \%)$ \\
Gestational $\geq 20$ weeks of gestation & $4(2.7 \%)$ \\
Diabetes & \\
Pre-existing & $2(1.4 \%)$ \\
Gestational & $40(27.2 \%)$ \\
Labor induction & $23(15.6 \%)$ \\
Dinoprostone & $15(10.2 \%)$ \\
Oxytocin & \\
Cesarean & $8(5.4 \%)$ \\
Scheduled cesarean & $22(15 \%)$ \\
Emergency, out of labor & $18(12.2 \%)$ \\
Emergency, during labor & $107(72.8 \%)$ \\
\hline
\end{tabular}

a Dinoprostone (Propess, Ferring laboratory, 94250 Gentilly, France).

b Oxytocin (Syntocinon, Sigma-Tau laboratory, 92130 Issy-les-Moulineaux, France). in the check list. This was followed by arrest of labor. This group is the main contributor to first cesarean section mainly potentially avoidable according to our results. For active phase in the first stage of labor, a prospective study of 542 women showed that extending the minimum period of oxytocin treatment from 2 to at least $4 \mathrm{~h}$ for active phase arrest in the first stage of labor allowed $92 \%$ of women to give birth vaginally without adversely affecting the neonatal outcome [12].

At the current time, various recommendations are available for the length of the second stage of labor $[8,9]$. The optimal duration depends more on the obstetrical team habits than a parameter that has been the subject of a precise methodology. In France, it was previously generally admitted that this time should not exceed $2 \mathrm{~h}$. Although recent studies have suggested a longer tolerance in the absence of non-reassuring fetal heart-rate tracing, this $2 \mathrm{~h}$ dilatation rule is still widely applied. American recommendations are in favor of a minimum delay of $3 \mathrm{~h}$ in the nulliparous women and $2 \mathrm{~h}$ in multiparous women [9]. Rouse et al. showed in a retrospective series of 4126 patients that the vaginal delivery rate was $55 \%$ beyond $3 \mathrm{~h}$ of arrest of labor [13].

The diagnosis of fetal head engagement in the maternal pelvis is sometimes difficult. This remains a subjective diagnosis, relying on operator experience and has a high error rate. Dupuis et al. find an error rate of $12 \%$ in the diagnosis of fetal head engagement, equally distributed between false positives and false negatives [14]. The "engagement ultrasound" seems to be a mandatory tool during the second stage of labor but its impact on cesarean section rate should 
Table 2

Overall indications for the first cesarean delivery. Values are expressed in numbers and percentage. In grey, the cesarean section eligible to Check List application.

\begin{tabular}{|c|c|c|c|}
\hline Indication & $n \quad C$ & eck list & $\%$ \\
\hline Arrest of labor & 117 & 89 & 20.5 \\
\hline Abnormal fetal-heart tracing & 150 & & 26.2 \\
\hline Fetal malpresentation & 62 & & 10.8 \\
\hline - Breech presentation & 55 & 39 & 9.6 \\
\hline - Other & 7 & & 1.2 \\
\hline Suspected fetal macrosomia & 22 & 19 & 3.8 \\
\hline Multiple gestation & 61 & & 10.7 \\
\hline - Twin gestation, first on breech presentation & 20 & & 3.5 \\
\hline - Other & 41 & & 7.1 \\
\hline Pre-eclampsia & 26 & & 4.5 \\
\hline Maternal & 16 & & 2.8 \\
\hline Materno-fetal & 48 & & 8.4 \\
\hline - Chorioamnionitis & 20 & & 3.5 \\
\hline - HELLP syndrome ${ }^{\mathrm{a}}$, retroplacental hematoma & 16 & & 2.8 \\
\hline - Placenta praevia & 2 & & 2.1 \\
\hline Obstetrical & 69 & & 12.1 \\
\hline - Induction of labor failure & 20 & & 3.5 \\
\hline - Other & 49 & & 8.6 \\
\hline Total & 571 & 147 & 100 \\
\hline
\end{tabular}

${ }^{a}$ HELLP syndrome: hemolysis elevated liver enzymes low platelet count syndrome.

be evaluate. Manual rotation of the fetal occiput could be an additional tool to reduce the first cesarean rate for posterior or transverse positions of the head. In the presence of this fetal head positions and in the case of successful manual rotation during the second stage of labor, the rate of cesarean would be between 0 and $9 \%$ depending on the author [15-17]. This attitude implies a precise knowledge of the position of the fetal head during labor with an error risk between 20 and 26.6\%, regardless of the operator's experience [18].

For breech presentations, the ACOG recommends a control of the presentation at 36 weeks of gestation and encourages the attempt to external cephalic version with an average success rate of about $50 \%$ according to the authors [19-21]. The ACOG does not mention the possibility of vaginal delivery in the case of external cephalic version failure. The CNGOF allows vaginal delivery of breech presentations if defined conditions are met. In France, the success rate of vaginal delivery attempts on a fetus in a breech presentation is between 65\% (according the Franco-Belgian PREMODA study) and 70\% (according to the French AUDIPOG sentinel network) $[22,23]$.

The ACOG and the HAS, CNGOF guidelines are in agreement concerning the first cesarean delivery for suspected fetal macrosomia $[7,24,25]$. In the absence of gestational diabetes, they recommends cesarean delivery if the fetal weight is greater than 5000 g. Despite these common Franco-American recommendations, in our study we found that this threshold was not followed in practice.

The strengths of our study reside in the contribution of a new tool, the checklist "First cesarean delivery" based on national, international guidelines and expert opinions. The weak points are firstly its retrospective design and the extrapolation of the vaginal success rate from literature to our series. Indeed, although almost half of the patients eligible for the checklist had at least one non conformity criteria of the checklist, we cannot extrapolate the final delivery outcome and conclude that all of these patients would undergo vaginal delivery. Secondly some of the check list items have a low level of recommendation such as ultrasound for fetal position or engagement diagnosis and fetal rotation of posterior positions. Our objective was to evaluate all the new available tools and their further potential impacts on cesarean section rate.

A prospective study should be therefore implemented. The checklist item could be use in the evaluation of professional practice as a health indicator.

\section{Conclusion}

Applying a checklist could to be an interesting tool in order to decrease the first cesarean delivery rate. A prospective study is now required to better analyze the impact of this checklist.

\section{Conflict of interest}

The authors report no conflict of interest.

\section{References}

[1] Brennan DJ, Robson MS, Murphy M, O'Herlihy C. Comparative analysis of international cesarean delivery rates using 10-group classification identifies significant variation in spontaneous labor. Am J Obstet Gynecol 2009;201(3). 308.e1-8.

[2] Barber EL, Lundsberg LS, Belanger K, Pettker CM, Funai EF, Illuzzi JL. Indications contributing to the increasing cesarean delivery rate. Obstet Gynecol $2011 ; 118(1): 29-38$.

[3] Zhang J, Troendle J, Reddy UM, Laughon SK, Branch DW, Burkman R. Contemporary cesarean delivery practice in the United States. Am J Obstet Gynecol 2010;203(4):326.e1-326.e10.

[4] Blondel B, Lelong N, Kermarrec M, Goffinet F. National Coordination Group of the National Perinatal Surveys. Trends in perinatal health in France from 1995 to 2010. Results from the French National Perinatal Surveys. J Gynecol Obstet Biol Reprod (Paris) 2012;41(4):e1-5.

[5] http://www.epopé-inserm.fr/wp-content/uploads/2017/10/ ENP2016_rapport_complet.

[6] Silver RM, Landon MB, Rouse DJ, Leveno KJ, Spong CY, Thom EA. Maternal morbidity associated with multiple repeat cesarean deliveries. Obstet Gynecol 2006;107(6):1226-32.

[7] Indications de la césarienne programmée à terme. HAS; 2012, https://www. has-sante.fr/portail/upload/docs/application/pdf/2012-03/ indications cesarienne programmee - fiche de synthese - indications.pdf.

[8] Accouchement normal; 2017. https://www.has-sante.fr/portail/jcms/ c_2820336/fr/accouchement-normal-accompagnement-de-la-physiologieet-interventions-medicales.

[9] American College of Obstetricians and Gynecologists (College), Society for Maternal-Fetal Medicine, Caughey AB, Cahill AG, Guise J-M, Rouse DJ. Safe prevention of the primary cesarean delivery. Am J Obstet Gynecol 2014:210(3): 179-93.

[10] Chaillet N, Dumont A, Abrahamowicz M, Pasquier JC, Audibert F, Monnier P. A cluster-randomized trial to reduce cesarean delivery rates in Quebec. N Engl J Med 2015;372(18):1710-21.

[11] Lasnet A, Jelen A-F, Douysset X, Pons J-C, Sergent F. [Introducing a daily obstetric audit: a solution to reduce the cesarean section rate?] J Gynecol Obstet Biol Reprod (Paris) 2015;44(6):550-7.

[12] Rouse DJ, Owen J, Hauth JC. Active-phase labor arrest: oxytocin augmentation for at least 4 hours. Obstet Gynecol 1999;93(3):323-8.

[13] Rouse DJ, Weiner SJ, Bloom SL, Varner MW, Spong CY, Ramin SM. Second-stage labor duration in nulliparous women: relationship to maternal and perinatal outcomes. Am J Obstet Gynecol 2009;201(4):357.e1-7.

[14] Dupuis O, Silveira R, Zentner A, Dittmar A, Gaucherand P, Cucherat M. Birth simulator: reliability of transvaginal assessment of fetal head station as defined by the American College of Obstetricians and Gynecologists classification. Am J Obstet Gynecol 2005;192(3):868-74.

[15] Le Ray C, Serres P, Schmitz T, Cabrol D, Goffinet F. Manual rotation in occiput posterior or transverse positions: risk factors and consequences on the cesarean delivery rate. Obstet Gynecol 2007;110(4):873-9.

[16] McQuivey RW, Reichman O, Gdansky E, Latinsky B, Labi S, Samueloff A. "Digital rotation from occipito-posterior to occipito-anterior decreases the need for 
cesarean section" [Eur. J. Obstet. Gynecol. Reprod. Biol. 136 (2008) 25-28]. Eur J Obstet Gynecol Reprod Biol 2013;171(2):e3-4.

[17] Shaffer BL, Cheng YW, Vargas JE, Caughey AB. Manual rotation to reduce caesarean delivery in persistent occiput posterior or transverse position. J Matern-Fetal Neonatal Med 2011;24(1):65-72.

[18] Dupuis O, Ruimark S, Corinne D, Simone T, André D, René-Charles R. Fetal head position during the second stage of labor: comparison of digital vaginal examination and transabdominal ultrasonographic examination. Eur J Obstet Gynecol Reprod Biol 2005;123(2):193-7.

[19] Laros RK, Flanagan TA, Kilpatrick SJ. Management of term breech presentation: a protocol of external cephalic version and selective trial of labor. Am J Obstet Gynecol 1995;172(6):1916-23. discussion 1923-5.

[20] Le Bret T, Grangé G, Goffinet F, Cabrol D. [External cephalic version: experience about 237 versions at Port-Royal maternity]. J Gynecol Obstet Biol Reprod (Paris) 2004;33(4):297-303.
[21] Lojacono A, Donarini G, Valcamonico A, Soregaroli M, Frusca T. [External cephalic version for breech presentation at term: an effective procedure to reduce the caesarean section rate]. Minerva Ginecol 2003;55(6):519-24.

[22] Vendittelli F, Rivière O, Pons JC, Mamelle N, Obstétriciens du Réseau Sentinelle AUDIPOG. [Breech presentation at term: evolution of French practices and an analysis of neonatal results in regards to obstetrical management of breech presentation, from AUDIPOG Database]. J Gynecol Obstet Biol Reprod (Paris) 2002;31(3):261-72.

[23] Carayol M, Alexander S, Goffinet F, Bréart G, Alexander S, Uzan S. Mode of delivery and term breech presentation in the PREMODA cohort. J Gynecol Obstet Biol Reprod (Paris) 2004;33(1 Suppl):S37-44.

[24] CNGOF 2000. Césarienne: conséquences et indications. http://www.cngof. asso.fr/data/RCP/cesarienne_2000.

[25] Chatfield J. ACOG issues guidelines on fetal macrosomia. American College of Obstetricians and Gynecologists. Am Fam Physician 2001;64(1):169-70. 